\title{
Crenças e comportamentos de pessoas com doença arterial coronária
}

\author{
Beliefs and behavior patterns \\ of individuals with coronary artery disease
}

Glicia Gleide Gonçalves Gama ${ }^{1}$

Fernanda Carneiro Mussi ${ }^{2}$

Cláudia Geovana da Silva Pires ${ }^{2}$

Armênio Costa Guimarães ${ }^{3}$
${ }^{1}$ Curso de Enfermagem, Escola Bahiana de Medicina e Saúde Pública (EBMSP). Rua Augusto Viana s/no, Canela. 41760-000 Salvador BA.

gliciaggama@gmail.com ${ }^{2}$ Escola de Enfermagem, Universidade Federal da Bahia.

${ }^{3}$ Faculdade de Medicina, Universidade Federal da Bahia.

\begin{abstract}
The study described beliefs and behavior patterns related to causes and control measures of coronary artery disease (CAD). A hundred adults in an outpatient clinic in Salvador in the state of Bahia were interviewed. The results were analyzed via the qualitative analysis technique. It predominantly involved married and unemployed black men, aged $<60$ years, with low schooling and income. The average beliefs on the cause of CAD was 1.53 per participant and blamed behavioral, biological, relational and religious factors, and represented excesses related to dayto-day tensions and eating habits. Most of the participants did not consider the disease to be chronic and believed that treatment would be temporary and they would be cured. The average beliefs for control measures were of 1.45, with dietary measures and medication. A sedentary lifestyle was the norm and reducing smoking and alcohol, using less salt and saturated fat in the preparation of meals, consuming white meat, cooked and industrialized food was seen as the answer. Only 66\% complied with medical prescriptions. Lack of understanding of the causes and control measures of CAD makes the implementation of medical care, better living and health conditions and self-care essential.
\end{abstract}

Key words Coronary artery disease, Risk factors, Behavior patterns, Beliefs
Resumo O estudo descreveu crenças e comportamentos sobre causas e medidas de controle da doença arterial coronária (DAC). Cem adultos foram entrevistados em ambulatório público, em Salvador (BA). Os resultados foram analisados em percentuais, médias e por técnica de análise de dados qualitativos. Predominaram homens, idade $<60$ anos, cor negra, baixas escolaridade e renda, casados e sem ocupação. A média de crenças para a causa da DAC foi de 1,53 por participante incluindo fatores comportamentais, biológicos, relacionais e religiosos e representaram sobretudo acúmulo de excessos quanto às tensões cotidianas e alimentação. A maioria dos participantes não considerou a enfermidade de caráter crônico acreditando que o tratamento não duraria a vida toda e na cura da doença. A média de crenças para medidas de controle foi de 1,45 prevalecendo seguimento do regime alimentar e uso das medicações. Predominou sedentarismo, redução do tabagismo e consumo de bebida alcoólica, preparo de alimentos com menos sal e gordura saturada, maior consumo de carnes brancas, alimentos cozidos e industrializados. Apenas 66\% cumpriam a receita médica. O entendimento insatisfatório sobre causas e medidas de controle da DAC torna essencial a implementação de cuidados contemplando as distintas condições de vida e saúde e projetos para o cuidar de si.

Palavras-chaves Doença da artéria coronariana, Fatores de risco, Comportamento, Crenças 


\section{Introdução}

As doenças cardiovasculares representam a maior causa de morbidade e mortalidade no mundo e importante problema de saúde pública ${ }^{1}$. No Brasil, em 1996, a mortalidade por doenças crônicas não transmissíveis, destacando-se as cardiovasculares, foi maior no Nordeste e, entre 1996 e 2007, diminuiu em todas as regiões do país, especialmente no Sul e Sudeste. Entretanto, em 2007 foi maior nas regiões mais pobres como o Norte e o Nordeste ${ }^{2}$.

Apesar dos recentes progressos na ciência e tecnologia, na área da saúde, que modificaram sobremaneira a evolução e o prognóstico da doença arterial coronária (DAC), é evidente o aumento da prevalência e mortalidade pela doença, pois o controle dos fatores de risco cardiovascular (FRCV) ainda é insatisfatório e para tal é necessário mudança de estilo de vida ${ }^{3}$. Reside aí o grande desafio a ser alcançado pela clientela, os profissionais de saúde e as autoridades públicas principalmente quando se propõe o controle de FRCV em população menos privilegiada, uma vez que variáveis socioeconômicas correlacionam-se de forma negativa com mortalidade por doença cardiovascular ${ }^{4}$.

É válido destacar que o contexto social exerce influência na definição dos modos de viver. Assim, mesmo considerando-se imprescindível a identificação dos FRCV clássicos, também é verdade que não basta identificá-los em um grupo, classificando indivíduos em padrões e estilos de vida. As estratégias somente terão êxito se considerarem a perspectiva das pessoas sobre o processo de adoecer e cuidar de si. Nesse sentido, condições socioeconômicas, perspectivas culturais, aspectos cognitivos, crenças e valores precisam ser considerados, pois podem estar diretamente implicados no comportamento relacionado ao seguimento do tratamento medicamentoso e não medicamentoso ${ }^{5}$.

Entende-se que as crenças dos indivíduos sobre a DAC precisam ser consideradas como fatores psicossociais que influenciam o gerenciamento da própria doença e revelam ideias, concepções e atitudes sobre o cuidado da própria saúde. As crenças são informações fornecidas pela família, pela sociedade, equipe de saúde, desde as mais remotas épocas, que passam de pais para filhos e são reforçadas pela cultura podendo variar entre as pessoas, de acordo com o tipo de doença, do meio social e podem influenciar as ações em saúde ${ }^{6}$. O termo comportamento tem origem latina: porto, que significa levar. Em por- tuguês passou à forma reflexiva "portar-se". É o conjunto organizado das operações selecionadas em função das informações recebidas do ambiente através das quais o indivíduo integra as suas tendências ${ }^{7}$. Em sentido mais amplo designa a mudança, o movimento ou a reação de qualquer entidade ou sistema em relação a seu ambiente ou situação.

O comportamento pode ser influenciado pelas crenças do indivíduo relacionadas à percepção subjetiva do risco de contrair determinada condição ou doença, do grau de sua severidade, dos benefícios e das barreiras para o seguimento de recomendações terapêuticas ${ }^{8}$. De acordo com as crenças pessoais sobre determinado comportamento, quanto às vantagens e desvantagens de assumi-lo, e com a pressão social percebida para agir de determinada forma em relação a ele, os indivíduos apresentarão graus diferentes de adesão ao comportamento estudado?.

A adoção das medidas de prevenção e controle da DAC, ou seja, o comportamento dos indivíduos, relacionados à prática de atividade físi$\mathrm{ca}$, ao preparo e consumo de alimentos, ao tabagismo, ao consumo de bebida alcoólica e ao cumprimento da receita médica, consiste em fator implicado na prevalência da morbidade e mortalidade pela doença. Tais comportamentos relacionam-se à escolha da forma de viver e a própria percepção de saúde que o indivíduo possui e tem de $\mathrm{si}^{10}$. Entende-se, também, que concepções equivocadas sobre as condições que favorecem o surgimento e a progressão da DAC podem levar à adoção de medidas de prevenção e controle inapropriadas. Se a concepção de saúde é formada por meio da experiência de cada indivíduo, tendo estreita relação com suas crenças, ideias, valores e aspectos emocionais, a forma com que percebe sua enfermidade pode influenciar os mecanismos individuais para satisfazer suas necessidades e a busca dos serviços assistenciais.

Considerando a importância do controle dos FRCV e, por conseguinte, da redução da morbidade e mortalidade por DAC e, que tal controle é influenciado pelas crenças e comportamentos, objetivou-se nesse estudo descrever as de indivíduos com DAC relativos à doença e ao controle dos FRCV.

Nesse sentido, este estudo possibilita uma reflexão sobre o cuidado interdisciplinar junto aos usuários dos serviços de saúde visando o controle de FRCV e para a proposição de intervenções culturalmente mais sensíveis ou ao menos não conflitivas, com os valores, costumes, tradições e crenças de um grupo ${ }^{11}$. Dar voz e aco- 


\section{Metodologia}

Trata-se de estudo de corte transversal, exploratório, realizado em um ambulatório de um hospital público, referência para atendimento em cardiologia para usuários do Sistema Único de Saúde (SUS), Salvador-BA.

Para o dimensionamento da amostra (n), tomou-se como parâmetro a prevalência estimada do infarto agudo do miocárdio (IAM) que é de 99/100.000 adultos em Salvador (BA) ${ }^{13}$. Foram também considerados no cálculo da amostra os seguintes parâmetros: $N$ - número total da população assumida durante o período da coleta de dados $=1.000 ; P$ - proporção dentro da população estudada $=0,099$; nível de significância de $5 \% ; B$ - erro máximo estimado; $Z_{\alpha / 2}=$ 1,$96 ; 1-\alpha=0,95 B=0,04$ ou $4 \%$. Estimou-se on com base na seguinte fórmula:

$$
\begin{gathered}
n=\frac{N P(1-P)}{(N-1) D+P(1-P)} \text { onde } \\
D=\frac{B^{2}}{Z_{\alpha / 2}} \text { e } P(|\hat{P}-P|<B)=1-\alpha .
\end{gathered}
$$

Estimou-se uma amostra composta por 100 indivíduos, cujos critérios de inclusão adotados foram: adultos, a partir de 18 anos, de ambos os sexos, conscientes, orientados no tempo e espaço, ou seja, em condições de entrevista, matriculados no ambulatório, com diagnóstico médico de IAM, angina e/ou submetidos a revascularização do miocárdio.

A primeira parte do instrumento de coleta de dados foi constituída de questões fechadas para levantar dados de caracterização sociodemográficos. A segunda, constou de perguntas fechadas e semiestruturadas para levantar as crenças e comportamentos relacionados à DAC e a seu controle, a exemplo de: $\mathrm{O}$ que você acha que causou a sua doença? O que você acredita que ajuda no controle da doença? Para você quanto tempo deve durar o tratamento da sua doença? etc.

O instrumento de coleta de dados foi previamente testado com dez indivíduos com diagnós-

tico médico de DAC visando verificar a adequação das questões para o levantamento de dados necessários ao estudo, bem como, o tempo médio de duração das abordagens. Constatou-se que as perguntas eram facilmente compreendidas pelos participantes e que a entrevista não excedia a uma hora.

A coleta de dados ocorreu no período de março a julho de 2008, sendo realizada por duas enfermeiras integradas ao projeto de pesquisa e previamente treinadas para manter a uniformidade da abordagem dos participantes e da aplicação do formulário.

Após a confirmação no prontuário do diagnóstico médico de DAC (IAM, angina ou revascularização do miocárdio) e da idade dos indivíduos que iriam passar ou tinham passado por consulta médica, estes eram abordados e convidados a participar da pesquisa. Ao demonstrarem interesse eram recebidos em uma sala privativa do ambulatório. Constatado que estavam em condições de participar da entrevista e após aquiescência ao estudo mediante assinatura do termo de consentimento livre e esclarecido, iniciava-se a aplicação do formulário. A amostragem foi não probabilística e os participantes foram selecionados por acessibilidade no decorrer do período de coleta de dados. A duração média das entrevistas foi de 40 minutos.

O projeto foi aprovado por Comitê de Ética em Pesquisa da Secretaria de Saúde do Estado da Bahia e respeitou os princípios éticos da Resolução 196/96 do Conselho Nacional de Saúde ${ }^{14}$.

As respostas dadas às questões semiestruturadas foram gravadas e, portanto, transcritas na íntegra e analisadas mediante emprego da técnica de análise de dados qualitativos proposta por Glaser ${ }^{15}$ visando identificar a natureza das crenças relacionadas à causa e ao controle da DAC. Nessa primeira fase da análise dos dados as respostas foram lidas exaustivamente e examinadas minuciosamente, linha por linha, para extrair os primeiros códigos (núcleos de sentido). Pelo processo de comparação, os códigos identificados foram agrupados por similaridades e diferenças formando as subcategorias que expressaram tanto a causa quanto o controle da doença. As subcategorias foram quantificadas.

Os dados das questões fechadas constituíram um banco de dados no programa estatístico SPSS 13.0 for Windows.

Os resultados foram analisados em números absolutos, percentuais e médias e apresentados em tabelas e gráficos. 


\section{Resultados}

\section{Características sociodemográficas e clínicas para DAC}

A amostra foi constituída em $56 \%$ por homens $(\mathrm{H})$ e $44 \%$ por mulheres $(\mathrm{M})$. A média de idade foi de $58,7 \pm 10,9$ anos $(\mathrm{H}=58,5$ e $\mathrm{M}=$ $58,9)$ predominando a faixa etária $<60$ anos (54\%). As procedências de Salvador (72\%) e Região Metropolitana (5\%) prevaleceram em relação a outras regiões da Bahia (23\%).

Oitenta e quatro por cento autodeclararamse pretos e pardos e $16 \%$ brancos. Quanto ao estado civil. $52 \%$ vivia com companheiro(a) e $48 \%$ eram separados, divorciados ou viúvos. A baixa escolaridade foi predominante, pois 34\% eram analfabetos e $53 \%$ cursaram até o primeiro grau, apenas $13 \%$ tinham até o segundo ou terceiro grau. Quanto à situação empregatícia, 68\% não tinham ocupação em razão da aposentadoria ou desemprego e $32 \%$ estavam empregados. A baixa renda foi característica já que $35 \%$ recebiam até um salário mínimo por mês, $47 \%$ de 1 a 2 e $18 \%$ três ou mais. Prevaleceu como número de dependentes de 1 a 3 (56\%), seguidos de 4 a $6(39 \%)$ e acima de seis (5\%). A metade deles submeteu-se ao primeiro atendimento no lócus de estudo em 2007 (50\%), 40\% em 2008 e 10\% em 2006.

Quanto ao modo de aquisição dos medicamentos prescritos, $40 \%$ apenas comprava, $49 \%$ comprava e recebia através do posto de saúde ou doações e $11 \%$ apenas recebia. Dos 89 indivíduos que compravam medicação, 71 (79,8\%) fazia uso do produto genérico, reduzindo os custos.

A caracterização da DAC mostrou que $82 \%$ dos indivíduos já haviam sofrido infarto do miocárdio, seguidos dos que apresentavam angina instável (18\%). Dos 82 indivíduos que tiveram IAM, a maioria $(85,4 \%)$ sofreu um evento, 9 (11\%) dois e $3(3,6 \%)$ três. Independente do tipo de evento coronário, 77,8\% daqueles com angina e $65,8 \%$ com IAM tiveram o diagnóstico médico há menos de um ano. Dez por cento foram matriculados no lócus de estudo em 2006 e 90\% nos anos de 2007 e 2008. Dos 90 participantes, 64 (71\%) haviam sofrido o último evento coronário há menos de um ano, retratando que parece coincidir o período de ocorrência do evento com o de atendimento no ambulatório de cardiologia preventiva.

\section{Crenças sobre a DAC e seu controle}

Dos 100 participantes, $17 \%$ relataram desconhecer o que causou a doença e $83 \%$ acreditavam que era causada por diferentes fatores como expressam as subcategorias no Quadro 1, sobressaindo-se estresse cotidiano (35\%), alimentação inadequada (28\%), fumo (19\%) e consumo excessivo de bebida alcoólica (11\%). A média de crenças associadas à causa da DAC foi de 1,53 por entrevistado.

Dezoito por cento relataram desconhecer as medidas de controle da DAC. Constatou-se também diferentes subcategorias de crenças a elas associadas, com destaque para seguimento do regime alimentar (34\%), uso das medicações prescritas pelo médico (27\%), redução do estresse diário (22\%), abdicação do fumo (15\%) e prática de atividade física (10\%). A média de crenças quanto às medidas de controle da DAC foi de 1,45 por participante.

Quanto às crenças sobre o tempo de tratamento da DAC, 67\% informaram não ter ideia de sua duração, $22 \%$ consideraram que deveria durar a vida toda, $8 \%$ menos que um ano e $3 \%$ de um a cinco anos. Com relação às crenças sobre a cura da DAC, $48 \%$ acreditavam que as medicações tomadas, a cirurgia ou a angioplastia eram capazes de curar a doença; $29 \%$ não tinham ideia se tais procedimentos promoveriam a cura e apenas $23 \%$ acreditavam que tais medidas não sanariam a DAC.

Catorze por cento informaram não ter recebido qualquer tipo de orientação da equipe de saúde para o controle da doença e $86 \%$ receberam mais de um tipo de orientação perfazendo a média de 2,4 orientações por participante. Dos 86 que receberam alguma informação, 76\% destacaram o regime alimentar, $34 \%$ o controle do estresse, $28 \%$ a prática de exercícios físicos, $26 \%$ o controle do peso, $19 \%$ a cessação do tabagismo, $15 \%$ o controle de ingestão de bebida alcoólica, $8 \%$ o uso de medicação e $1 \%$ a realização de cirurgia.

\section{Comportamentos relacionados ao controle da DAC}

Dos 100 participantes, $37 \%$ nunca fumaram e $4 \%$ eram tabagistas. No entanto, $59 \%$ referiram ser ex-tabagistas, e destes $81,4 \%$ deixaram de fumar há mais de 2 anos, 13,5\% há menos de um ano e $5,1 \%$ entre um e dois anos. 
Quadro 1. Participantes segundo crenças sobre as causas e medidas de controle da DAC. Salvador-BA.

\begin{tabular}{|c|c|c|c|c|}
\hline Categorias & Subcategorias & & Códigos & $\mathbf{n}$ \\
\hline \multirow[t]{3}{*}{$\begin{array}{l}\text { Crenças } \\
\text { sobre as } \\
\text { causas da } \\
\text { DAC }\end{array}$} & $\begin{array}{l}\text { Viver } \\
\text { preocupações e } \\
\text { tensões no dia } \\
\text { a dia }\end{array}$ & $\begin{array}{l}\text { O que levou a coisa foi aborrecimento. Em } \\
\text { casa, problema com os filhos... Uma (filha), } \\
\text { foi a que me deu mais problema, foi que. } \\
\text { fez, como é que se diz, coisa errada, a } \\
\text { caçula e com pessoa errada. Eu não sentia } \\
\text { nada, eu não sentia nada não. Aí comecei } \\
\text { a sentir pressão, problema de pressão, } \\
\text { coração... } \\
\text { Estresse, viu? Acho que foi estresse, que } \\
\text { hoje em dia pra se viver aí é um negócio } \\
\text { sério, viu? Acho que foi através disso. Acho } \\
\text { que foi mesmo... }\end{array}$ & $\begin{array}{l}\text { Sendo as tensões vividas dia-a-dia; sendo o } \\
\text { estresse do dia a dia; tendo muito esforço } \\
\text { mental; passando preocupação; vivendo } \\
\text { muito estresse; tendo muito nervoso; não } \\
\text { dormindo devido ao trabalho; passando } \\
\text { raiva com o marido; tendo aborrecimento } \\
\text { com o filho; passando preocupação por } \\
\text { problema financeiro; vivendo preocupações; } \\
\text { vivendo trabalho estressante; vivendo } \\
\text { aborrecimentos; vivendo um dia a dia de } \\
\text { trabalho corrido; vivendo muita ansiedade; } \\
\text { tendo trabalho estressante; passando } \\
\text { esgotamento; tendo depressão. }\end{array}$ & 35 \\
\hline & $\begin{array}{l}\text { Exceder na } \\
\text { alimentação }\end{array}$ & $\begin{array}{l}\text { Eu acho que a gente come, dana a comer } \\
\text { gordura.... E é a má alimentação, a falta } \\
\text { de educação na alimentação }\end{array}$ & $\begin{array}{l}\text { Faltando educação na alimentação; Não se } \\
\text { alimentando direito; Usando muito sal; } \\
\text { usando muita gordura; comendo de tudo; } \\
\text { comendo gordura; não fazendo dieta; } \\
\text { comendo comida pesada; comendo comida } \\
\text { gorda; comendo mal no trabalho; } \\
\text { alimentando-se mal nas viagens. }\end{array}$ & 28 \\
\hline & Fumar cigarro & $\begin{array}{l}\text { Eu estava até fumando cigarro... foi } \\
\text { quando eu tava fumando cigarro, daí já } \\
\text { comecei com aquela agonia... } \\
\text { Ouvi dizer que era coisa do cigarro né? }\end{array}$ & $\begin{array}{l}\text { Fumando cigarro; vivendo com o marido } \\
\text { que fumava. }\end{array}$ & 19 \\
\hline \multirow{4}{*}{$\begin{array}{l}\text { Crenças } \\
\text { sobre as } \\
\text { medidas de } \\
\text { controle da } \\
\text { DAC }\end{array}$} & $\begin{array}{l}\text { Exceder-se na } \\
\text { bebida } \\
\text { alcoólica }\end{array}$ & $\begin{array}{l}\text { Eu sempre gostei muito de cachaça... Acho } \\
\text { que foi muita cachaçá, né? }\end{array}$ & $\begin{array}{l}\text { Bebendo muito; bebendo muita cachaça; } \\
\text { excedendo na bebida. }\end{array}$ & 11 \\
\hline & $\begin{array}{l}\text { Fazer esforço } \\
\text { físico }\end{array}$ & $\begin{array}{l}\text { Olha, o médico falou que foi o desgaste } \\
\text { físico, muito. Porque trabalho desde } \\
\text { pequena, que trabalho. E o meu trabalho } \\
\text { sempre foi assim, né? De limpeza, muita } \\
\text { coisa pesada mesmo... } \\
\text { Foi exatamente, o que me causou isso tudo } \\
\text { aí foi esforço de trabalho... }\end{array}$ & $\begin{array}{l}\text { Sendo muito esforço físico; pegando coisas } \\
\text { pesadas; trabalhando pesado; pegando muito } \\
\text { peso; pegando saco de cimento. }\end{array}$ & 9 \\
\hline & $\begin{array}{l}\text { Ter a doença } \\
\text { na família }\end{array}$ & $\begin{array}{l}\text { É, acho que é de família. Já morreu um } \\
\text { irmão meu, morreu a minha mãe. Eu } \\
\text { tenho uma irmã operada. Morreu agora } \\
\text { um em Natal. Até a família toda é assim, } \\
\text { quando não é derrame, é infarto... } \\
\text { Porque a família minha toda tem } \\
\text { problema, né? Morrer assim de infarto, } \\
\text { num instante. Pode ser família. }\end{array}$ & $\begin{array}{l}\text { Sendo de família; sendo hereditária; só tava } \\
\text { faltando eu da família. }\end{array}$ & 8 \\
\hline & Ter pressão alta & $\begin{array}{l}\text { Eu também sou hipertenso, não me } \\
\text { cuidava bem não vou mentir, entendeu? } \\
\text { Não tinha assim um certo cuidado com a } \\
\text { pressão alta e acho que causou isso aí... }\end{array}$ & Tendo pressão alta; tendo pico hipertensivo. & 7 \\
\hline
\end{tabular}




\begin{tabular}{|c|c|c|c|c|}
\hline \multicolumn{5}{|c|}{ Quadro 1. continuação } \\
\hline Categorias & Subcategorias & & Códigos & $\mathbf{n}$ \\
\hline \multirow[t]{7}{*}{$\begin{array}{l}\text { Crenças } \\
\text { sobre as } \\
\text { causas da } \\
\text { DAC }\end{array}$} & Ter diabetes & $\begin{array}{l}\text { Que aí o coração veio me atacar depois do } \\
\text { diabete.. Eu comecei a me tratar do } \\
\text { diabete em } 84 \text {. Até hoje ainda sofro de } \\
\text { diabete, o açúcar sobe, o açúcar desce... } \\
\text { O médico cardiologista me falou, que foi o } \\
\text { problema de diabetes, que eu tenho trinta } \\
\text { e um anos com diabetes... }\end{array}$ & $\begin{array}{l}\text { Sendo o diabetes; sendo o problema do } \\
\text { diabetes. }\end{array}$ & 6 \\
\hline & $\begin{array}{l}\text { Ter gordura alta } \\
\text { no sangue }\end{array}$ & $\begin{array}{l}\text { Aquelas, as gorduradas que a gente come, } \\
\text { essas coisas toda. Então, ela vai } \\
\text { acumulando ali nas laterais da veia, eu } \\
\text { acho, né? Aí elas vão fechando, fechando. } \\
\text { eu tenho um problema muito alto de } \\
\text { colesterol. O meu colesterol se eleva por } \\
\text { qualquer coisa até emocionalmente o meu } \\
\text { colesterol se eleva. Como eu não vinha } \\
\text { fazendo a dieta programada do primeiro } \\
\text { infarto ocasionou o segundo infarto... }\end{array}$ & Sendo a gordura alta no sangue. & 6 \\
\hline & $\begin{array}{l}\text { Ter doença } \\
\text { reumática }\end{array}$ & $\begin{array}{l}\text { Os médicos acham que foi uma febre } \\
\text { reumática que eu tive em criança, } \\
\text { entendeu? E eu tive mermo essa febre }\end{array}$ & Sendo devido à febre reumática na infância. & 2 \\
\hline & $\begin{array}{l}\text { Não fazer } \\
\text { atividade física }\end{array}$ & É, eu acho que foi é... a vida sedentária... & $\begin{array}{l}\text { Tendo vida sedentária; não fazendo } \\
\text { exercício. }\end{array}$ & 2 \\
\hline & $\begin{array}{l}\text { Ter idade } \\
\text { avançada }\end{array}$ & $\begin{array}{l}\text { Eu acho que depois dos } 50 \text { aparece as } \\
\text { coisas mesmo... }\end{array}$ & Depois dos 50 aparecem as coisas mesmo. & 1 \\
\hline & $\begin{array}{l}\text { Não seguir as } \\
\text { orientações } \\
\text { médicas }\end{array}$ & $\begin{array}{l}\text { Os médicos me mandavam fazer as coisas, } \\
\text { mas eu não seguia, não tinha vontade de } \\
\text { fazer dieta, nem de andar todo dia... }\end{array}$ & Não fazendo o que o médico diz. & 1 \\
\hline & Usar drogas & $\begin{array}{l}\text { Eu fumei muita maconha, que naquele } \\
\text { tempo de música... }\end{array}$ & Fumando maconha. & 1 \\
\hline \multirow[t]{2}{*}{$\begin{array}{l}\text { Crenças } \\
\text { sobre as } \\
\text { medidas } \\
\text { de controle } \\
\text { da DAC }\end{array}$} & Fazer dieta & $\begin{array}{l}\text { Melhorando a alimentação... eu não sou de } \\
\text { comer essas comida demais, eu como pouco. } \\
\text { Não como gordo, não como salgado... } \\
\text { Ter um controle da alimentação daqui por } \\
\text { diante, né? E se conscientizar de que é } \\
\text { preciso mudar hábitos alimentares... } \\
\text { Então...eu acho que hoje, minha } \\
\text { consciência o que me faz não ter outro } \\
\text { infarto talvez seja alimentação, educação } \\
\text { para alimentação... }\end{array}$ & $\begin{array}{l}\text { Fazendo educação alimentar; não comendo } \\
\text { muita coisa; não comendo muito açúcar; } \\
\text { controlando a alimentação; não comendo } \\
\text { gordura; tendo boa alimentação; não } \\
\text { comendo salgado; tendo um controle da } \\
\text { alimentação; comendo de tudo um } \\
\text { pouquinho; fazendo dieta; tendo } \\
\text { alimentação balanceada; não abusando do } \\
\text { sal; não comendo salgado e gorduroso; } \\
\text { fazendo minha dieta; tomando chá, } \\
\text { melhorando a alimentação. }\end{array}$ & 34 \\
\hline & $\begin{array}{l}\text { Usar a } \\
\text { medicação } \\
\text { prescrita }\end{array}$ & $\begin{array}{l}\text { O que ajuda? Eu acho que os remédio, né? } \\
\text { Ajuda bastante. Então, em primeiro lugar } \\
\text { os remédios... } \\
\text { Remédio, né? Tô tomando remédio, muito } \\
\text { remédio. Eu sou uma farmácia... }\end{array}$ & $\begin{array}{l}\text { Tomando medicamento, tomando remédio } \\
\text { direitinho; tomando medicamento na hora } \\
\text { certa; tendo medicamento. }\end{array}$ & 27 \\
\hline
\end{tabular}




\begin{tabular}{|c|c|c|c|c|}
\hline \multicolumn{5}{|c|}{ Quadro 1. continuação } \\
\hline Categorias & Subcategorias & & Códigos & $\mathbf{n}$ \\
\hline \multirow[t]{6}{*}{$\begin{array}{l}\text { Crenças } \\
\text { sobre as } \\
\text { medidas } \\
\text { de controle } \\
\text { da DAC }\end{array}$} & $\begin{array}{l}\text { Diminuir o } \\
\text { estresse do dia } \\
\text { a dia }\end{array}$ & $\begin{array}{l}\text { Rapaz, é melhorar esse estresse. Procurar } \\
\text { melhorar, procurar me preocupar menos } \\
\text { entendeu? }\end{array}$ & $\begin{array}{l}\text { Melhorando o estresse; conhecendo o que é } \\
\text { a doença para ter tranquilidade; distraindo- } \\
\text { se; tendo controle emocional; não tendo } \\
\text { preocupação; Tendo calma; Tendo } \\
\text { paciência; Não sendo estressada; Tendo } \\
\text { lazer; Não se aborrecendo. }\end{array}$ & 22 \\
\hline & Não fumar & $\begin{array}{l}\text { Eu não vou negar, é o parar de fumar né? É } \\
\text { um vício horrível, vício de cigarroEntão, é } \\
\text { não fumar cigarro... }\end{array}$ & $\begin{array}{l}\text { Parando de fumar; Não fumando cigarro; } \\
\text { Não sendo fumante passivo. }\end{array}$ & 15 \\
\hline & $\begin{array}{l}\text { Praticar } \\
\text { exercício/ } \\
\text { atividade física }\end{array}$ & $\begin{array}{l}\text { Onde eu moro, o conjunto é grande, eu faço } \\
\text { caminhadas, que aí já é um exercício, pra } \\
\text { mim andar duas horas por dia, duas de } \\
\text { manhã, duas de tarde... Eu acho que } \\
\text { atividade física poderia, se o médico me } \\
\text { liberar, pode me ajuda ... }\end{array}$ & $\begin{array}{l}\text { Fazendo exercício; fazendo atividade física; } \\
\text { não tendo vida sedentária; tendo uma } \\
\text { atividade física, fazendo caminhadas. }\end{array}$ & 10 \\
\hline & $\begin{array}{l}\text { Confiar na } \\
\text { religião }\end{array}$ & $\begin{array}{l}\text { Além de medicamentos, pedir a Deus } \\
\text { porque sem Deus ninguém é nada, não é } \\
\text { verdade? Então quem tem fé em Deus } \\
\text { nunca cai... } \\
\text { Os meus orixás mandam eu fazer, eu vou } \\
\text { olhar no jogo o que é, aí é pra eu fazer } \\
\text { aquilo, eu faço. Me sinto bem... }\end{array}$ & $\begin{array}{l}\text { Tendo fé em Deus; acreditando em Jesus; } \\
\text { fazendo o que os orixás mandam. }\end{array}$ & 7 \\
\hline & Não beber & $\begin{array}{l}\text { Evito tomar uma pinga, eu aguento, eu digo } \\
\text { não vou tomar que pode fazer mal, aí não } \\
\text { bebo... }\end{array}$ & Evitando tomar uma pinga; não bebendo. & 6 \\
\hline & $\begin{array}{l}\text { Receber o } \\
\text { melhor } \\
\text { tratamento } \\
\text { médico }\end{array}$ & $\begin{array}{l}\text { Hoje em dia, consegui melhorar graças a } \\
\text { Deus com o tratamento que eu tive aqui... }\end{array}$ & $\begin{array}{l}\text { Equipe fazendo tudo para salvar; recebendo } \\
\text { bom tratamento; fazendo cirurgia; sendo } \\
\text { controlado pela enfermeira e médicos. }\end{array}$ & 5 \\
\hline
\end{tabular}

Predominou o uso de cigarros para fumantes e ex-fumantes $(74,6 \%)$ seguido de charuto $(14,3 \%)$ e cachimbo $(11,1 \%)$ e a quantidade de mais de 20 cigarros por dia (50,8\%). Com relação ao uso de bebidas alcoólicas, $26 \%$ nunca beberam, 23\% referiram ingestão atual e 51\% abandono do consumo, a maioria $(70,6 \%)$ há mais de 2 anos. Quanto a prática de exercício físico, $76 \%$ a negaram, $5 \%$ a realizavam menos de 3 vezes por semana com duração menor do que 30 minutos e apenas 19\% a realizava mais do que 3 vezes por semana, por no mínimo 30 minutos.

Quanto a forma de preparo dos alimentos a Tabela 1 ilustra a redução do uso de sal e gordura depois do evento cardiovascular. Como for- ma de preparo atual dos alimentos predominou a cozida $(46,3 \%)$ e assada $(33,6 \%)$. Ainda 9,2\% preparavam os alimentos fritos. Atualmente, os participantes utilizavam mais de um tipo de gordura no preparo dos alimentos sobressaindo-se o óleo de soja $(37,8 \%)$, de girassol $(16,3 \%)$ e o azeite de oliva (14,1\%). Mais da metade (57\%) preparava a sua própria refeição.

Com relação ao consumo atual de alimentos, a Tabela 2 mostra que os participantes usavam mais de um tipo de carne branca (galinha sem pele $-39,2 \%$ e peixe $-17,7 \%$ ), seguida de carne de boi $(31,8 \%)$. Quanto ao uso de ovos $36 \%$ não consumiam, $40 \%$ comiam de um a dois e $13 \%$ menos que um por semana. O consumo 
Tabela 1. Participantes segundo informações dadas sobre o preparo dos alimentos. Salvador -BA.

\begin{tabular}{|c|c|c|}
\hline Preparo dos alimentos & $\mathbf{N}$ & $\%$ \\
\hline \multicolumn{3}{|l|}{ Sal antes do evento ${ }^{*}(\mathrm{n}=100)$} \\
\hline Mais & 79 & 79 \\
\hline Médio & 16 & 16 \\
\hline Menos & 5 & \\
\hline \multicolumn{3}{|l|}{ Sal depois do evento ${ }^{*}(\mathrm{n}=100)$} \\
\hline Mais & 1 & 1 \\
\hline Médio & 31 & 31 \\
\hline Menos & 68 & 68 \\
\hline \multicolumn{3}{|c|}{ Acrescenta sal no alimento pronto $(\mathrm{n}=100)$} \\
\hline Não & 87 & 87 \\
\hline Sim & 7 & \\
\hline Às vezes & 6 & \\
\hline \multicolumn{3}{|l|}{ Gordura antes do evento ${ }^{*}(\mathrm{n}=100)$} \\
\hline Mais & 85 & 85 \\
\hline Médio & 11 & 11 \\
\hline Menos & 4 & \\
\hline \multicolumn{3}{|l|}{ Gordura depois do evento ${ }^{*}(\mathrm{n}=100)$} \\
\hline Mais & 4 & \\
\hline Médio & 28 & 28 \\
\hline Menos & 68 & 68 \\
\hline \multicolumn{3}{|l|}{ Preparo atual dos Alimentos $(\mathrm{n}=164)^{* *}$} \\
\hline Cozidos & 76 & 46,3 \\
\hline Assados & 55 & 33,6 \\
\hline Grelhados & 18 & 10,9 \\
\hline Fritos & 15 & 9,2 \\
\hline \multicolumn{3}{|l|}{ Tipo atual de gordura usada $(\mathrm{n}=185)^{* *}$} \\
\hline Óleo Soja & 70 & 37,8 \\
\hline Óleo Girassol & 30 & 16,3 \\
\hline Azeite Oliva & 26 & 14,1 \\
\hline Margarina sólida & 16 & 8,6 \\
\hline Margarina Cremosa & 12 & 6,5 \\
\hline Azeite Dendê & 11 & 5,9 \\
\hline Óleo Côco & 11 & 5,9 \\
\hline Manteiga & 9 & 4,9 \\
\hline \multicolumn{3}{|l|}{ Prepara a própria refeição $(\mathrm{n}=100)$} \\
\hline Sim & 57 & 57 \\
\hline Não & 43 & 43 \\
\hline
\end{tabular}

"O evento corresponde à Síndrome Coronariana Aguda. " Os participantes mencionaram mais de uma forma de preparo dos alimentos e tipo de gordura utilizada

de alimentos industrializados como bolos e biscoitos prevaleceu nos lanches de $61 \%$ dos entrevistados, assim como, o uso de refrigerantes (80\%). O consumo diário de café destacou-se, pois $67 \%$ bebiam de 1 a 2 xícaras por dia. Noventa e seis por cento realizavam as refeições no domicílio.

Dos 86 participantes que informaram ter recebido alguma recomendação terapêutica para o controle da DAC, 53 (62\%) relataram aderência e 33 (38\%) o não seguimento. Os motivos apon-
Tabela 2. Participantes segundo o consumo atual de alimentos. Salvador - BA.

$\begin{array}{lll}\text { Consumo atual de alimentos } & \text { N } & \%\end{array}$

Tipo de carne $(\mathrm{n}=176)^{*}$

Galinha sem pele

Carne de boi

$69 \quad 39,2$

Peixe

Vísceras

Carne de Porco

Galinha com pele

Não come carne

$56 \quad 31,8$

$31 \quad 17,7$

Consumo semanal de ovos $(\mathrm{n}=100)$

$<1$ ovo/semana $\quad 13 \quad 13$

1 ovo $18 \quad 18$

2 ovos $\quad 22 \quad 22$

$\geq 3$ ovos $11 \quad 11$

Não consome $\quad 36 \quad 36$

Consumo de bolos e biscoitos $(\mathrm{n}=100)$

$\begin{array}{lll}\text { Sim } & 61 & 61\end{array}$

Não $\quad 39 \quad 39$

Consumo de café $(\mathrm{n}=100)$

$1-2$ xícaras $^{* *} /$ dia $\quad 67 \quad 67$

$\geq 3$ xícaras $^{* *} /$ dia $\quad 28 \quad 28$

< 3 xícaras $^{* *}$ na semana $\quad 1 \quad 1$

Não consome 44

Consumo de refrigerantes $(n=100)$

Sim $\quad 80 \quad 80$

Não $20 \quad 20$

Local de realização da refeição $(\mathrm{n}=100)$

Casa $\quad 96 \quad 96$

Restaurante 22

Trabalho $\quad 2 \quad 2$

*A maioria dos participantes mencionaram mais de um tipo de carne consumida. ${ }^{* *}$ A xícara referida é de tamanho regular $(\sim 150 \mathrm{~mL})$

tados pelos 33 participantes para o não seguimento de orientações da equipe de saúde recaíram sobre a condição econômica deficitária $(24,2 \%)$, a dificuldade para a modificação dos hábitos alimentares $(24,2 \%)$, ao estresse $(12,1 \%)$, a não valorização do tratamento $(12,1 \%)$ e a falta de orientação continuada $(9,2 \%)$.

Dos 100 participantes apenas $66 \%$ referiram cumprimento integral da receita médica. Entre os motivos para não seguimento do tratamento medicamentoso, informados por $34 \%$, prevaleceram às condições econômicas deficitárias $(41,2 \%)$, aonde destes, $71,4 \%$ tinham renda menor ou igual a um salário mínimo mensal e 28,6\% recebiam de um a dois. Evidenciou-se também o 


\section{Discussão}

O grupo estudado é considerado de alto risco cardiovascular já que tinha DAC prévia e apresentou características socioeconômicas homogêneas, era dependente de atendimento pelo SUS, oriundo basicamente da cidade de Salvador e Região Metropolitana, declarou-se majoritariamente de raça/cor negra e vivia em condições de desigualdade social evidenciada pela baixa escolaridade e renda familiar e inatividade profissional, em razão de aposentadoria ou desemprego. Estes achados confirmam as descrições na literatura nacional ${ }^{4,16,17} \mathrm{e}$ internacional ${ }^{18}$ dessas características como potencializadoras do risco de doença cardiovascular.

A maioria dos participantes parecia não compreender a sua enfermidade como de caráter crônico, pois não tinha ideia sobre o tempo de tratamento e acreditava que entre 1 a 5 anos haveria cura. Apenas 22\% expressaram a enfermidade como uma condição que os acompanharia ao longo da trajetória de vida e que as medidas terapêuticas deveriam ser constantes. De modo coerente com a crença de que havia um tempo determinado para o tratamento da DAC ou mesmo com a falta de ideia sobre a sua duração, a maioria entendia que as medicações tomadas, a cirurgia ou a angioplastia realizadas eram capazes de promover a cura ou não tinha ideia sobre a eficácia desses procedimentos. Pode-se inferir que tais crenças deixam transparecer uma concepção reducionista do corpo, da doença como uma avaria do corpo ${ }^{19}$, bem como, que alguns usuários parecem delegar a responsabilidade por sua saúde ao médico, aos medicamentos e aos procedimentos médicos. Para alguns, pode-se considerar que a preocupação em prevenir a ocorrência de novos eventos cardiovasculares pode ter sido minimizada em razão da não compreensão de que a DAC é crônica e demanda medidas de controle de longa duração.

Os participantes também evidenciaram ideias, convicções e atitudes sobre causas e medidas de prevenção e controle DAC. Chamou a atenção que 17 relataram não ter ideia sobre a causa e 18

sobre as medidas para seu controle. Para aqueles que expressaram suas crenças observou-se correlação dos fatores causais e de controle com o que é ancorado pelo conhecimento técnico científico, a exemplo da hereditariedade, dieta, atividade física, estresse, tabagismo, etc. As crenças sobre a causa da DAC representaram predominantemente um acúmulo de excessos referentes à alimentação, ao fumo, às tensões cotidianas $\mathrm{e}$ ao esforço físico (Quadro 1).

Prevaleceram crenças sobre causas associadas ao nervosismo, às preocupações, conflitos nas relações familiares e no trabalho, que condensam os aspectos físicos, morais e emocionais, juntamente com os socioeconômicos e com a violência, concentrada e evidente em alguns espaços urbanos ${ }^{11}$. Além disso, as condições gerais da existência, no plano material, moral e relacional, confluem a importante categoria sociossomática do nervosismo para explicar a origem da doença ${ }^{20}$ (Quadro 1).

A formação desse grupo de crenças sobre a causa da DAC pode ter sido influenciada por autoridades tendo como referência os profissionais de saúde, por informações oriundas de meios de comunicação de massa e/ou pelo próprio costume. Outras, por sua vez, refletiram a identificação com alguma autoridade divina, a exemplo da crença de que o controle da doença ocorre tendo fé em Deus, acreditando em Jesus e fazendo o que os orixás mandam. Outras crenças depositaram o poder de cura em entidades externas a si mesmo, ao considerarem que a ação da equipe de saúde daria conta de sanar o mal que os afligia (Quadro 1).

As crenças sobre o quadro causal da DAC composto pelos participantes deste estudo coincidem com as explicações sobre a causalidade da diabetes expressas por uma mulher em um estudo de caso $^{20}$ que incluiu fatores comportamentais (hábito alimentar), biológicos (herença genética) e relacionais (ambientais, pessoais e sociais). Embora a média de crenças associadas à causa da DAC tenha sido baixa revelando a compreensão limitada sobre os fatores determinantes da doença a partir da lógica da racionalidade médico-científica, o conjunto identificado mostra que a noção de causalidade entre os segmentos populares é pluralística e se unifica nas explicações que incluem aspectos de ordem natural, socioeconômica e psicossocial ${ }^{21,22}$.

Com relação às medidas de controle da DAC a média de crenças por participante foi também reduzida apontando a baixa compreensão sobre a natureza e a extensão do tratamento não medi- 
camentoso recomendado pelo conhecimento biomédico (Quadro 1). Todavia, o grupo de crenças sobre essas medidas expressou, em sua maioria, os fatores associados à ocorrência e progressão da DAC e que o controle depende do regime de vida adotado pelo enfermo. Regime esse que impõe práticas restritivas à alimentação e ao consumo de bebidas, bem como, a incorporação de novos hábitos como atividade física, uso de medicamentos etc.

Esses resultados assinalam que os profissionais de saúde precisam ouvir os usuários dos serviços e compreender o significado da experiência para o adoecido. Precisam conhecer suas crenças, preferências, condições e perspectivas sobre e para o cuidar de si. É importante, compreender, junto com os indivíduos, as relações que estabelecem entre o adoecer, sua história de vida, seu modo de viver e os FRCV atrelados à DAC ${ }^{23}$. Embora outros fatores estejam implicados na mudança de comportamento, entende-se que raciocinar sobre o que leva à ação de determinada maneira poderá contribuir para a mudança ${ }^{9}$.

Nessa perspectiva, os profissionais de saúde talvez possam transcender a ação de informar o sentido e os benefícios do controle dos FRCV e quiçá ajudar os usuários a também transcender a interiorização das recomendações não somente como restrições, representando o fardo da doença, mas a valorizar e identificar novas formas de ser e de viver, a incorporar a necessidade de mudança como forma de preservação de um bem maior, a própria existência ${ }^{5}$. O desafio está em alcançar a valorização da necessidade de mudança de hábitos como parte essencial do tratamento e ajudar a tornar mais fácil a passagem de uma condição para outra, especialmente em estratos socioeconômicos onde as margens de escolha para um estilo de vida saudável praticamente inexistem.

É válido destacar que alguns participantes lograram êxito na incorporação de novos hábitos de vida. No que se refere ao aspecto comportamental, mais especificamente sobre os hábitos alimentares, verificou-se que afirmaram redução significativa do consumo de sódio e evitaram o saleiro à mesa, além de uma redução do consumo de gordura após o evento coronário (Tabela 1). Passaram, ainda a preparar os alimentos, preferencialmente, de forma cozida, assada ou grelhada (Tabela 2). No entanto, parte deles continuava utilizando mais de um tipo de gordura no preparo dos alimentos, salientando-se, entre elas, as com alto teor de gordura como o azeite dendê (11\%) e o óleo de coco (11\%) (Tabela 1).
Embora soubessem dos benefícios do uso do óleo de girassol e de oliva, apontaram como principal justificativa para o uso de outros o menor custo associado à condição econômica deficitária.

Observou-se, também, o consumo de alimentos de grande teor calórico e baixo teor nutritivo, como de bolos e biscoitos industrializados e refrigerantes (Tabela 2). Estes alimentos tendem a ser ricos em gorduras vegetais saturadas e transinsaturadas, todas com elevado poder aterogênico. Uma barreira apontada para o seguimento das orientações foi a dificuldade para modificação dos hábitos alimentares. Algumas recomendações para o controle da DAC consistem em restrições altamente frustrantes, pois determinam a privação de prazeres da vida, desafiando os profissionais de saúde na formulação de cardápios mais atrativos e adequados às preferências e às condições econômicas dos participantes.

A dieta é outro ponto de discrepância entre as prescrições médicas oficiais e as ações efetivadas pelos adoecidos, revelando uma inviabilidade e incompatibilidade das orientações de caráter clínico diante do mundo da vida ${ }^{24}$. Reside aí o desafio em minimizar a distância entre as recomendações e as práticas. Além disso, alimentos com alto teor energético têm um valor simbólico para a classe trabalhadora por prover as energias, a recuperação e a manutenção da força física, associada às representações de saúde, como disposição para o trabalho ${ }^{24}$.

O consumo de carne de boi com ou sem gordura visível foi citado por $56 \%$, de 2 ou mais ovos por semana por 33\% (não sendo possível identificar a forma do seu preparo, pois um ovo frito, principalmente na manteiga, tende a aumentar o seu poder aterogênico) e de café diário por $95 \%$ (Tabela 2). Tais hábitos somados à constatação da falta de exercício físico e a evidência de outros fatores de risco estiveram associados a um controle ineficaz do perfil lipídico, de sobrepeso e obesidade, de circunferência abdominal aumentada e de níveis pressóricos elevados, retratados em outro estudo também desenvolvido com esta amostra ${ }^{25}$.

Não era esperado que 14 participantes referissem não ter recebido qualquer tipo de orientação para o controle da doença, inclusive por estarem sendo acompanhados em atendimento ambulatorial, a maioria de um a dois anos. Há que se considerar, também, a possibilidade de falta de lembrança, não valorização ou assimilação de algo recomendado pela equipe de saúde. Além disso, apesar de 86 participantes terem recebido mais de um tipo de orientação, perfazen- 
do a média de 2,4 orientações por participante, era de se esperar uma média superior a esta, tendo-se em vista a gama de FRCV modificáveis e não modificáveis e da presença de DAC na vida desses indivíduos.

Evidenciou-se também que, dos 86 participantes que informaram receber alguma orientação para o controle da DAC, 33 relataram dificuldades para colocá-las em prática, sobretudo em razão das condições econômicas deficitárias. Além disso, apesar de 53 indivíduos informarem o seguimento das orientações da equipe de saúde para DAC, não pôde ser identificado no estudo se incorporaram na vida cotidiana todas ou apenas algumas das recomendações terapêuticas. A reprodução das recomendações não corresponde apenas a observá-las integralmente (fato que intriga os profissionais de saúde), pois os comportamentos se orientam, em parte, por conceitos, critérios, princípios, fatores e valores às vezes incompatíveis com as prescrições, requerendo que ajustes sejam feitos ${ }^{20}$.

Da mesma forma, não foi possível identificar se a não adesão foi ampla ou restrita a algumas das recomendações médicas, excetuando-se para a terapêutica medicamentosa. No particular, constatou-se que 34\% dos entrevistados relataram não cumprir integralmente a receita médica também em razão da deficiência econômica e da falta de estrutura dos serviços de saúde no provimento dos remédios receitados (dos 34, 62\% comprava ou recebia pelo menos alguma medicação prescrita). Surpreendeu o fato de apenas $11 \%$ receberem gratuitamente a totalidade das medicações prescritas.

Mesmo com a implantação de políticas que visam o acesso aos medicamentos no Brasil, como os genéricos e as listas de medicamentos essenciais, muitas prescrições trazem medicamentos não acessíveis à grande parte da população, impossibilitando o seguimento do tratamento prescrito $^{25}$, o que precisa ser considerado pela equipe médica em prol do seguimento do tratamento medicamentoso. Além disso, apesar dos gastos com fármacos representarem grande parte do investimento em saúde pública, a disponibilização gratuita de tais medicamentos não cobre as necessidades da população.

Autores apontam que é comum, no acompanhamento dos indivíduos, a irregularidade do tratamento medicamentoso, muitas vezes ligada à falta de recursos financeiros para adquirir $o$ remédio, quando este não é encontrado na instituição ${ }^{26}$. O esquecimento da medicação seja pelo participante ou por seu familiar, e a falta de ori- entação para o seu uso foram ressaltados pelos participantes e implica na adoção de práticas de cuidar em enfermagem que favoreçam aos clientes a identificação correta do nome, da dose, da via e do horário das medicações, bem como, dos efeitos desejados e benefícios obtidos quando do seu uso correto.

Sabe-se que o poder aquisitivo influencia o consumo de alimentos e medicamentos, mas é insuficiente para explicar o não seguimento e as reformulações alimentares feitas pelos adoecidos que são intermediadas pelas normas culturais e pela ideologia (forma de pensar socialmente construídas) que cercam os usos, a seleção dos alimentos, a aprendizagem e a socialização do que comer, e marcam identidades e particularidades dos grupos sociais ${ }^{23}$. Assim, a flexibilidade nas praticas dietéticas é influenciada tanto pela produção, oferta e acesso e distribuição dos alimentos, quanto por fatores culturais e ideológicos relativos às ideias sobre os alimentos, as crenças nas suas propriedades e aos efeitos que os acompanham, envolvendo valores sociais, noções de moralidade, comportamentos apropriados entre os distintos grupos de idade e gênero, permeado pela ainda identidade social, relações com o corpo e o gosto ${ }^{24}$. Qualquer ação eficaz para mudança de atitude somente poderá ocorrer se a pessoa estiver motivada e contar com suportes imprescindíveis da estrutura econômica e social ${ }^{5}$.

A não adesão ao tratamento precisa ser assumida como um problema de múltiplas dimensões, já que vários fatores podem estar envolvidos como sociodemográficas (idade, escolaridade, nível socioeconômico), características da doença (cronicidade, sintomatologia); crenças e hábitos culturais, tratamento (custo, reações indesejáveis, esquemas complexos); instituição (acesso, acolhimento), relacionamento com os profissionais de saúde, etc ${ }^{27}$. A partir desta compreensão e com ações integradas da equipe de saúde junto aos usuários dos serviços e sua rede de apoio social, pode-se traçar estratégias de prevenção e controle mais eficazes.

\section{Considerações finais}

Neste estudo, evidenciou-se pessoas em condição de desigualdade social, com entendimento insatisfatório sobre as medidas de controle da DAC e baixa adesão ao tratamento medicamentoso e não medicamentoso. É preciso pensar, implementar e avaliar cuidados em saúde que 
contemplem as distintas condições de vida, potencialidades de saúde e sobrevivência destes indivíduos.

O estudo implica em profunda reflexão dos profissionais de saúde sobre as práticas de cuidar visando a prevenção e o controle da DAC. Aponta para a necessidade do desenvolvimento de atividades educativas, relacionadas ao controle dos FRCV, com linguagem acessível ao nível de compreensão desta clientela, a serem implementadas e monitoradas de forma extensiva e continuada e baseadas em peculiaridades socioeconômicas e nas crenças em saúde dos usuários dos serviços de saúde. É essencial que os indivíduos possam ser auxiliados a compreender a importância da terapêutica e a utilizar os recursos que dispõem de forma mais adequada e atrativa para a prevenção de novos eventos coronários.

Por meio de uma abordagem interdisciplinar que vise a integralidade das ações da equipe de saúde e a apreensão das reais necessidades dos indivíduos atendidos, bem como, através da proposição de terapêuticas medicamentosas e não medicamentosas viáveis de implementação pelos usuários poderá se obter melhor êxito no controle dos FRCV.

\section{Colaboradores}

GGG Gama, FC Mussi participaram da concepção do estudo, da coleta, interpretação e análise dos dados, redação e revisão do artigo. CGS Pires participou da coleta de dados, da revisão do artigo e da adequação às normas da revista. AC Guimarães participou da interpretação e da análise dos dados. 


\section{Referências}

1. Brasil. Ministério da Saúde (MS). Secretaria de Vigilância em Saúde. Secretaria de Gestão Estratégica e Participativa. VIGITEL BRASIL - 2006. Vigilância de fatores de risco e proteção para doenças crônicas por inquérito telefônico. Brasília: MS; 2007.

2. Schmid MI, Duncan BB, Silva GA, Menezes AM, Monteiro CA, Barreto SA, Chor D, Menezes PR. Doenças crônicas não transmissíveis no Brasil: carga e desafios atuais. The Lancet. [periódico na Internet]. 2011 maio [acessado 2011 out 22]:61-74. Disponível em: http://download.thelancet.com/flatcontentassets/pdfs/brazil/brazilpor4.pdf

3. Moriguchi EH. Novos fatores de risco na prática clínica. Hipertensão 2002; 5(2):63-66.

4. Ishitani LH, Franco GC, Perpétuo IHO, França E. Desigualdade social e mortalidade precoce por doenças cardiovasculares no Brasil. Rev. Saude Publica 2006; 40(4):864-891.

5. Mussi FC. O infarto e a ruptura com o cotidiano: possível atuação da enfermagem na prevenção. Latino-am Enferm 2004; 12(5):751-759.

6. Pires CGS, Mussi FC. Crenças em saúde para o controle da hipertensão arterial. Cien Saude Colet 2008; 13(2):2257-2267.

7. Ávila FB. Pequena enciclopédia de moral e civismo. 2a Edição. Rio de Janeiro: Fename, Ministério da Educação e Cultura; 1972.

8. Dela Coleta MF. Modelos para pesquisa e modificação de comportamentos de saúde. Teorias, estudos e instrumentos. Taubaté, SP: Cabral editora e livraria universitária; 2004.

9. Cavalcanti APR, Dias MR, Rodrigues CFF, Gouveia CNNA, Ramos DD, Serrano FJO. Crenças e influências sobre dietas de emagrecimento entre obesos de baixa renda. Cien Saude Coletiva 2007; 12(6):15671574 .

10. Silqueira SMF, Moura LF, Jardim AR. A importância de uma assistência diferenciada ao cliente hipertenso visando à adesão ao tratamento proposto. In: Anais do $8^{\circ}$ encontro de extensão da UFMG; 2005; Belo Horizonte.

11. Canesqui AM, organizador. Olhares sócio-antropológicos sobre os adoecidos crônicos. 1a Edição. São Paulo: Hucitec, Fapesp; 2007.

12. Pontieri FM, Bachion MM. Crenças de pacientes diabéticos acerca da terapia nutricional e sua influência na adesão ao tratamento. Cien Saude Colet 2010; 15(1):151-160.

13. Lessa I. Epidemiologia das doenças cerebrovasculares no Brasil. Rev Soc Cardiol Estado de São Paulo 1999; 9(4):509-518.

14. Brasil. Ministério da Saúde. Conselho Nacional de Saúde. Normas de pesquisa envolvendo seres humanos - Res. CNS 196/96. Bioética 1996; 4(Supl. 2): 15-25.

15. Glaser B. Theoretical sensitivity. Mill Valley, CA: Sociology Press; 1978.
16. Kaiser SE. Aspectos epidemiológicos na doença coronariana e cerebrovascular. Rev SOCERJ 2004; 17(1):11-18.

17. Lessa I, Araújo MJ, Magalhães L, Almeida Filho N, Aquino E, Costa MCR. Clustering of modifiable cardiovascular risk factors in adults living in Salvador (BA), Brazil. Rev Panam Salud Publica 2004; 16(2):131-137.

18. Yusuf S, Reddy S, Ounpuu S, Anand S. Global burden of cardiovascular diseases: Part II: Variations in cardiovascular disease by specific ethnic groups and geographic regions and prevention strategies. Circulation 2001; 104(23):2855-2864.

19. Capra F. O modelo biomédico. In: Capra F, organizador. O ponto de mutação: a ciência, a Sociedade e a Cultura emergente. Tradução de Álvaro Cabral. São Paulo: Editora Cultrix; 1986. p. 106-155.

20. Barsaglini RA. Com açúcar no sangue até o fim: um estudo de caso sobre o viver com diabetes. In: $\mathrm{Ca}$ nesqui AM, organizadora. Olhares sócio-antropológicos sobre adoecidos crônicos. São Paulo: Hucitec; 2007. p. 53-85.

21. Ngokwey N. Pluralistic Etiological Systems in their Social Context: A Brazilian Case Study. London. Soc. Sci. Med 1988; 26(8):793-802.

22. Minayo MCS. Saúde-doença: uma concepção popular da etiologia. Cad Saude Publica 1988; 4(4):363381.

23. Mussi FC. Desconforto, modelo biomédico e enfermagem: reflexões com base na experiência de homens infartados. Acta Paul Enferm 2003; 16(3):88-97.

24. Canesqui AM, Garcia RWD. Antropologia e nutricão: um diálogo possível. Rio de Janeiro: Fiocruz; 2005.

25. Gama GGG, Mussi FC, Mendes AS, Guimarães AC. (Des)controle de parâmetros clínicos e antropométricos em indivíduos com doença arterial coronária. Rev. Esc. Enferm. USP 2011; 45(3):624-631.

26. Leite SN, Vieira M, Veber AP. Estudos de utilização de medicamentos: uma síntese de artigos publicados no Brasil e América Latina. Cien Saude Colet 2008; 13(Supl):793-802.

27. Santos ZMSA, Frota MA, Cruz DM, Holanda SDO. Adesão do cliente hipertenso ao tratamento: análise com abordagem interdisciplinar. Texto \& Contexto Enferm 2005; 14(3):332-340.

Artigo apresentado em 05/08/2011

Aprovado em 01/11/2011

Versão final apresentada em 13/10/2011 